\title{
EDITORIAL
}

\section{Antisense as an explanatory, experimental and therapeutic tool for psychiatric disorders ${ }^{1}$}

Molecular biology has helped uncover several curiosities in genetic processes relevant to psychiatry. The latest example of these is antisense. The existence of antisense genes represents another potential form of genetic regulation, while the manipulation of antisense gene fragments has considerable experimental and, more speculatively, therapeutic applications. Here, we try to make sense of antisense and discuss its psychiatric significance.

\section{THE PRINCIPLES OF ANTISENSE}

The principles of antisense are best understood in relation to gene expression. Gene expression is the pathway along which the information encoded by genes on DNA is converted, via an intermediate called messenger RNA (mRNA), into proteins (see Fig. 1) (Harrison \& Pearson, 1989). Gene expression is controlled by several factors, including those which affect the distribution and abundance of each mRNA. These factors in turn play a key role in regulating the synthesis of the encoded protein. Together, these processes ensure that the information contained in our genes is realized in the proteins required for development and normal functioning (Harrison, 1994).

Two points about the language of the genetic code are relevant for understanding antisense. First, DNA is double-stranded, with the two entwined strands said to be complementary to each other. Information coded on a strand of nucleic acid is directional and the complementary strands are lined up in opposite orientations (called $5^{\prime} \rightarrow 3^{\prime}$ and $3^{\prime} \rightarrow 5^{\prime}$, see Fig. 1), with the genetic code always read in the $5^{\prime} \rightarrow 3^{\prime}$ direction. The second, crucial, point is that a gene is normally encoded by only one of the two DNA strands at any given chromosomal location, and the complementary strand at that point is not used to make mRNA.

This asymmetry of gene expression between the two DNA strands forms the basis for defining antisense. The term originated in contrast to the strand of DNA or RNA which encodes a protein, called the sense strand. Antisense genes are those which are located on the strand complementary to the sense strand, such that both strands of DNA at that point code for proteins. The term antisense is now used more generally to describe any length of DNA or RNA which is complementary to a length of coding strand DNA or RNA. Because complementary strands will always bind (hybridize) to each other given the chance, the presence of an antisense strand in a cell should, under suitable conditions, lead to a double-stranded nucleic acid being formed. The significance of this is that double-stranded nucleic acids have very different properties from the single-stranded form: notably, mRNA cannot be translated or used to synthesize its protein. Arising from these principles, antisense is predicted to inhibit, or prevent, expression of the respective sense strand gene (Fig. 1). This, indeed, proves to be the case and has led to a flourishing research field where the molecular processes, experimental uses and therapeutic potential of antisense are being investigated (Hélène \& Toulmé, 1990; Weintraub, 1990; Lancet Editorial 1991).

\section{NATURAL AND EXPERIMENTAL ANTISENSE}

Antisense genes are relatively common in lower organisms, where they are thought to control gene

' Address for correspondence: Dr P. J. Harrison, University Department of Psychiatry, Warneford Hospital, Headington, Oxford OX3 7JX. 


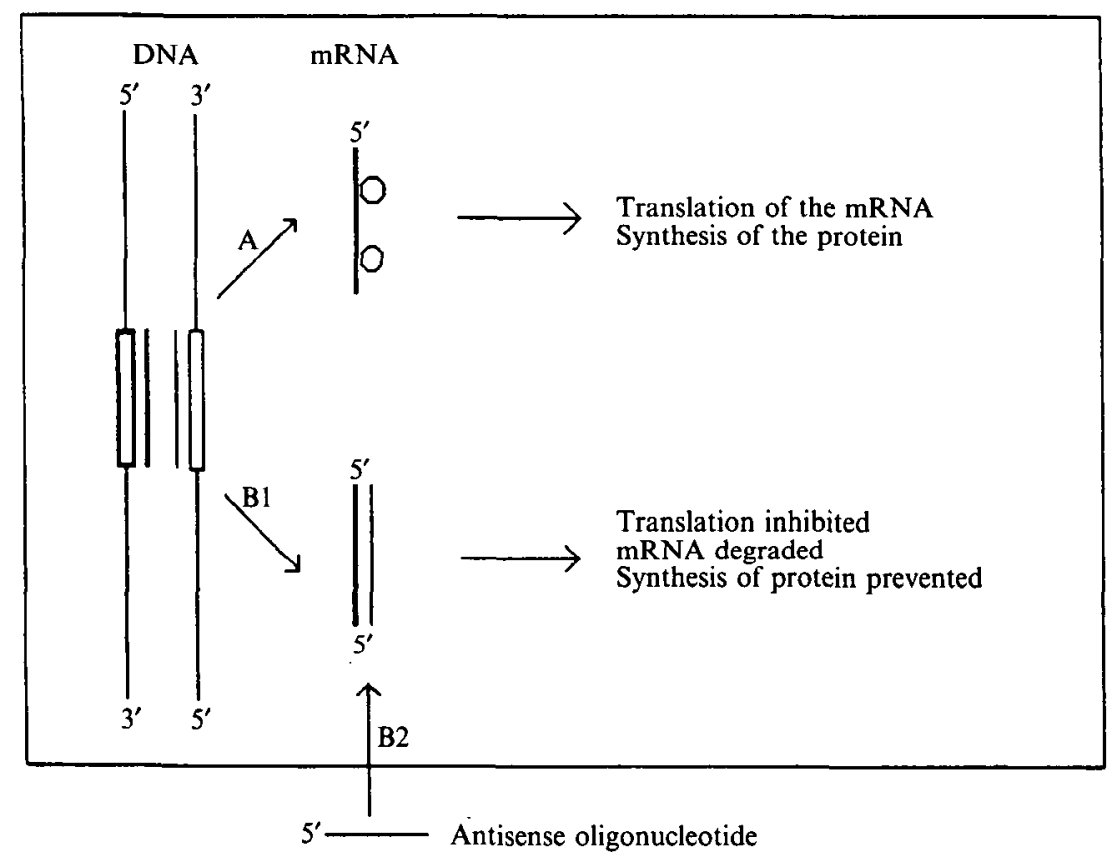

Fig. 1. To make a protein, the gene sequence on chromosomal DNA is first copied into a strand of messenger RNA (mRNA). The mRNA then moves to the cytoplasm where it attaches to a ribosome (circles) for translation and protein synthesis (path A). Normally, only one of the two strands of DNA encodes a gene (shown as the box with bold outline) and gives rise to mRNA (bold line). An antisense gene is one which occurs at the same location on the other DNA strand (box with thin outline). The mRNA arising from an antisense gene is shown as a thin line (path Bl). Antisense DNA targeted against a mRNA can also be introduced into the cell experimentally in the form of an oligonucleotide (path B2). From either source, the antisense sequence hybridizes to the target mRNA because the two are of opposite orientation and complementary to each other (see text). Formation of an antisense-sense hybrid has several effects that serve to prevent translation of the mRNA and, therefore, stop synthesis of the encoded protein.

expression (Takayama \& Inouye, 1990). In higher animals, including humans, antisense genes only seem to exist as fragments, and they lack some of the features shared by normal (sense) genes. At least one such antisense gene fragment is expressed in the brain (Adelman et al. 1987; Takayama \& Inouye, 1990; Dolnick, 1993). In addition, there are genes that have a sequence complementary to a sense gene, or part of it, but which are encoded at a different site in the genome; they, therefore, cannot be called true antisense genes, but their sequence complementarity suggests they have antisense-like effects. This phenomenon may be involved in regulation of the prion protein gene (Moser et al. 1993), the key pathogenic factor in prion diseases (e.g. Creutzfeldt-Jakob disease). Thus, although the number and biological importance of antisense genes in human brain remains unclear, these examples illustrate that they exist and may contribute to the genetic regulation of brain function and its involvement in psychiatric disorders.

The main interest in antisense lies in the development of experimental methods by which antisense gene fragments can be used to regulate gene expression in the same way that natural antisense genes are thought to (Fig. 1). One approach is to insert an antisense gene into the genome of cells in culture or in transgenic animal embryos (Takayama \& Inouye, 1990). This technique has been used, for example, to block the expression and function of the mouse myelin basic protein gene (Katsuki et al. 1988) and to investigate the functions of the Alzheimer's disease amyloid precursor protein gene (LeBlanc et al. 1992). However, manipulation of the genome in this way is of limited relevance for psychiatric disorders, for which temporary and localized inhibition of brain gene expression is likely to be of greater value. The rest of the discussion therefore refers to antisense inhibition of mRNA (Fig. 1, pathway B2), which allows this form of control because cells only make a mRNA 
if and when they are synthesizing the protein for which it codes; other cells lack the mRNA and will be immune to the antisense effect.

It transpires that the antisense inhibition of gene expression requires only a short fragment of DNA complementary to part of the target mRNA. This finding has greatly helped the experimental applications of antisense, since short lengths of single-stranded DNA, called oligonucleotides, are easy to synthesize and use. Initially, it was shown that addition of an antisense oligonucleotide to a cell culture medium inhibits the expression of that gene in the cells and thereby causes a loss of function mediated by the encoded protein. For example, the microtubule-associated protein tau is needed for developing neurons to form neurites (the precursors of axons and dendrites); an oligonucleotide against tau mRNA prevents them from doing so (Caceres \& Kosik, 1990). Many other genes have had their expression inhibited by antisense oligonucleotides in this way in vitro in cell culture (e.g. Listerud et al. 1991) and also in brain slices where the physiological consequences can be tested more clearly (Vanderklish et al. 1992).

Although the promise of gene expression inhibition by antisense oligonucleotides was predicted on the theoretical grounds of the genetic code mentioned above, its success in practice is quite surprising. Enzymes which avidly degrade fragments of DNA or RNA occur in all tissues and might have been expected to destroy the oligonucleotide before it could act. In fact, oligonucleotides are stable for several hours in cerebrospinal fluid and serum (Akhtar \& Juliano, 1992; Whitesell et al. 1993). Also, it was thought that oligonucleotides would be unable to cross the cell membrane and would have to be injected into a cell directly. However, this has not proved to be the case, a fact probably explained by the identification of a specific membrane transport protein (Loke et al. 1989) and supported by the discovery that RNA can be taken up by neurons and transported retrogradely (Jirikowski et al. 1992).

The mechanism of action of experimental antisense is proposed to be that hybridization of the oligonucleotide to its target mRNA prevents translation of the mRNA on the ribosome. This results in degradation of the mRNA by ribonuclease enzymes and prevents synthesis of the protein (Fig. 1). In practice, the success of antisense inhibition is capricious and it is not clear exactly how it occurs (Hélène \& Toulmé, 1990; Eguchi et al. 1991). For example, the oligonucleotide may enter the nucleus, where it can impair the formation or maturation of the mRNA. In some ways it does not matter precisely how the effect is produced as long as the desired specific inhibition of gene expression results. In the long term, however, a clear understanding of the mechanisms will be needed before antisense can feasibly be extended to therapeutic roles (see below).

Despite the success of experimental antisense inhibition in vitro being somewhat unexpected and unexplained, its efficacy has recently led researchers to apply similar methods in rat brain in vivo (Harrison, 1993). Again, it has proved fruitful. The antisense oligonucleotide is injected into the lateral ventricle, following which the neurochemical and behavioural consequences are measured. The first demonstration was to reduce expression of the neuropeptide Y1 receptor by over $50 \%$ (Wahlestedt et al. 1993a). The neuropeptide Y1 receptor is implicated in neural mechanisms of anxiety, and its down-regulation by antisense was indeed accompanied by increased anxiety in the animals. A range of controls confirmed that the effect was due to specific inhibition of this gene. These data showed that the synthesis of a protein, coded by a specific mRNA, can be inhibited in the brain and lead to the anticipated loss of the functions mediated by the protein. A second powerful example of antisense in vivo was the inhibition of synthesis of the NMDA glutamate receptor (NMDAR1 subunit). This receptor mediates excitotoxicity after brain hypoxia. After occlusion of the middle cerebral artery, the size of the infarcted brain area was significantly lower in the antisense treated rats, in parallel with a $50 \%$ reduction in NMDA receptor numbers (Wahlestedt et al. 1993 b). As a third demonstration of the potential of this approach, the expression of the $\mathrm{D}_{2}$ dopamine receptor has been suppressed by an antisense oligonucleotide (Weiss $e t$ al. 1993). All these experiments produced a similar functional effect as blockade of the receptor with an antagonist; one major advantage of the antisense approach is that an oligonucleotide can be designed which is highly unlikely to interfere with any other mRNA, whereas receptor ligands are rarely wholly specific and often have an undesired affinity for other receptors. 
More spatially discrete effects on gene expression may be possible by putting the antisense directly into the brain substance. Chiasson and colleagues injected an antisense oligonucleotide into the striatum and prevented expression of the target gene there but not in the contralateral striatum (Chiasson et al. 1992). They also showed that the effect was dose-dependent and lasted only a few hours, confirming the transience of oligonucleotide actions. This form of localized administration of antisense combines molecular specificity with anatomical selectivity and will contribute to the pharmacological characterization of individual receptors in different brain areas.

The experimental potential of antisense is apparent from these examples. The data suggest that it is a specific, reversible and non-toxic way to suppress the expression of a gene in the living brain and to investigate its biochemical and functional consequences. Issues germane to neurodevelopment, neurotoxicity, disease pathogenesis, and psychotropic drug mechanisms are all candidates for study in this way. It represents a simple form of selective genetic manipulation which complements that of transgenic animals and other methods for modifying neuronal gene expression such as gene transfer. Together these techniques provide a range of powerful ways to investigate and modify brain function, and they will have a major impact on both basic and clinical neurosciences (Neve, 1993).

\section{THERAPEUTIC POTENTIAL OF ANTISENSE}

The molecular specificity of antisense oligonucleotides and the reversible nature of their effects make them ideal candidates for a new type of drug. The demonstration that cerebral infarct size is reduced by inhibiting NMDA receptor synthesis is an obvious example of their therapeutic potential (Wahlestedt et al. 1993 b). Other areas showing promise include suppression of HIV gene expression (Leonetti et al. 1990) and inhibition of oncogenes, which are involved in the pathogenesis of cancers and other disease processes (Cohen, 1992; Simons et al. 1992).

Novel psychotropic agents can be envisaged based on the same antisense principles. For example, selective reduction of $\mathrm{D}_{4}$ dopamine receptor expression could produce a clozapine-like antipsychotic, since this drug has been proposed to act primarily by antagonism at the $\mathrm{D}_{4}$ dopamine receptor (Van Tol et al. 1991), while antisense suppression of the prion protein gene might slow the onset or progression of prion disease (Prusiner, 1992). In disorders due to an autosomal dominant mutation, the antisense oligonucleotide could be designed to be complementary only to the abnormal form of the mRNA, leaving the mRNA arising from the normal copy of the gene (inherited from the other parent) unaffected (Chang et al. 1991). There are undoubtedly many unresolved clinical issues of pharmacodynamics, pharmacokinetics, reliability and toxicity; there are also lingering doubts about the validity of some antisense findings which must be overcome by replication and extension of the current data (Stein \& Cheng, 1993; Wagner et al. 1993). One of the main problems relevant to psychiatric applications is likely to be finding a feasible method for getting intact and stable antisense molecules into the brain. In practice, it will be necessary to give the oligonucleotide in a form which allows intravenous or even intramuscular injection; such manoeuvres might include packaging it in liposomes which can be targeted to specific cell populations (Leonetti et al. 1990; Zhu et al. 1993). Chemical modifications of the oligonucleotide are valuable for increasing its half-life but may compromise its cellular uptake or molecular specificity (Akhtar \& Juliano, 1992; Khan \& Coulson, 1993; Whitesell et al. 1993). Drug companies are already taking an interest in tackling these issues (Moffat, 1991). In the meantime, neuroscientists continue to explore the uses of antisense in understanding brain function through the modulation of gene expression, while molecular biologists investigate the occurrence of antisense genes and clarify exactly how the effects of natural and experimental antisense are produced.

PAUL J. HARRISON AND PHILIP W. J. BURNET 


\section{REFERENCES}

Adelman, J. P., Bond, C. T., Douglass, J. \& Herbert, E. (1987). Two mammalian genes transcribed from opposite strands of the same DNA. Science 235, 1514-1517.

Akhtar, S. \& Juliano, R. L. (1992). Cellular uptake and intracellular fate of antisense oligonucleotides. Trends in Cell Biology 2, 139-144.

Caceres, A. \& Kosik, K. S. (1990). Inhibition of neurite polarity by tau antisense oligonucleotides in primary cerebellar neurons. Nature 343, 461-463.

Chang, E. H., Miller, P. S., Cushman, C., Devadas, K., Pirollo, K. F., Ts'o, P. O. P. \& Yu, Z. P. (1991). Antisense inhibition of ras p2l expression that is sensitive for a point mutation. Biochemistry 30, 8283-8286.

Chiasson, B. J., Hooper, M. L., Murphy, P. R. \& Robertson, H. A. (1992). Antisense oligonucleotide eliminates in vivo expression of c-fos in mammalian brain. European Journal of Pharmacology, Molecular Pharmacology Section 227, 451-453.

Cohen, J. (1992). Oligonucleotide therapeutics. Neuroscience Facts 3, part $4,1-2$.

Dolnick, B. J. (1993). Cloning and characterization of a naturally occurring antisense RNA to human thymidylate synthase mRNA. Nucleic Acids Research 21, 1747-1752.

Eguchi, Y., Itoh, T. \& Tomizawa, J.-I. (1991). Antisense RNA. Annual Review of Biochemistry 60, 631-652.

Harrison, P. J. (1993). Antisense: into the brain. Lancet 342 , 255-256.

Harrison, P. J. ed. (1994). Regulation of Gene Expression and Brain Function. Basic and Clinical Aspects of Neuroscience, vol. 6 (series eds. C. Weil, E. E. Müller and M. O. Thorner). Springer Verlag: Heidelberg.

Harrison, P. J. \& Pearson, R. C. A. (1989). Gene expression and mental disease. Psychological Medicine 19, 813-819.

Hélène, C. \& Toulmé, J.-J. (1990). Specific regulation of gene expression by antisense, sense and antigene nucleic acids. Biochimica et Biophysica Acta 1049, 99-125.

Jirikowski, G. F., Sanna, P. P., Maciejewski-Lenoir, D. \& Bloom, F. E. (1992). Reversal of diabetes insipidus in Brattleboro rats: intrahypothalamic injection of vasopressin mRNA. Science 255 , 996-998.

Katsuki, M., Sato, M., Kimura, M., Yokoyama, M., Kobayashi, K. \& Nomura, T. (1988). Conversion of normal behaviour to shiverer by myelin basic protein antisense cDNA in transgenic mice. Science 241, 593-596.

Khan, I. M. \& Coulson, J. M. (1993). A novel method to stabilise antisense oligonucleotides against exonuclease degradation. $\mathrm{Nu}$ cleic Acids Research 21, 2957-2958.

Lancet Editorial (1991). Antisensibility: progress and prospects. Lancet 338, 1427-1428.

LeBlanc, A. C., Kovacs, D. M., Chen, H. Y., Villaré, F., Tykocinski, M., Autilio-Gambetti, L. \& Gambetti, P. (1992). Role of amyloid precursor protein (APP): study with antisense transfection of human neuroblastoma cells. Journal of Neuroscience Research 31, 635-645.

Leonetti, J.-P., Machy, P., Degols, G., Lebleu, B. \& Leserman, L. (1990). Antibody-targeted liposomes containing oligodeoxyribonucleotides complementary to viral RNA selectively inhibit viral replication. Proceedings of the National Academy of Sciences, USA 87, 2448-2451.
Listerud, M., Brussaard, A. B., Devay, P., Colman, D. R. \& Role, L. W. (1991). Functional contribution of neuronal AChR subunits revealed by antisense oligonucleotides. Science 254, 1518-1521.

Loke, S. L., Stein, C. A., Zhang, X. H., Mori, K., Nakanishi, M. Subasinghe, C., Cohen, J. S. \& Neckers, L. M. (1989). Characterization of oligonucleotide transport into living cells. Proceedings of the National Academy of Sciences, USA 86, 3474-3478.

Moffat, A.S. (1991). Making sense of antisense. Science 253, 510-511.

Moser, M., Oesch, B. \& Büeler, H. (1993). An anti-prion protein? Nature 362, 213-214.

Neve, R. L. (1993). Adenovirus vectors enter the brain. Trends in Neurosciences 16, 251-253.

Prusiner, S. B. (1992). Natural and experimental prion diseases of humans and animals. Current Opinion in Neurobiology 5, 638-647.

Simons, M., Edelman, E. R., DeKeyser, J.-L., Langer, R. \& Rosenberg, R. D. (1992). Antisense c-myb oligonucleotides inhibit intimal arterial smooth muscle cell accumulation in vivo. Nature 359, 67-70.

Stein, C. A. \& Cheng, Y.-C. (1993). Antisense oligonucleotides as therapeutic agents - is the bullet really magical? Science 261, 1004-1012.

Takayama, K. M. \& Inouye, M. (1990). Antisense RNA. Critical Reviews in Biochemistry and Molecular Biology 25, $155-184$.

Vanderklish, P., Neve, R., Bahr, B. A., Arai, A., Hennegriff, M., Larson, J. \& Lynch, G. (1992). Translational suppression of a glutamate receptor subunit impairs long-term potentiation. Synapse 12, 333-337.

Van Tol, H. H. M., Bunzow, J. R., Guan, H.-C., Sunahara, R. K., Seeman, P., Niznik, H. B. \& Civelli, O. (1991). Cloning of the gene for a human $D_{4}$ receptor with high affinity for the antipsychotic clozapine. Nature 350, 610-614.

Wagner, R. W., Matteucci, M. D., Lewis, J. G., Gutierrez, A. J., Moulds, C. \& Froehler, B. C. (1993). Antisense gene inhibition by oligonucleotides containing C-5 propyne pyrimidines. Science 260 , 1510-1513.

Wahlestedt, C., Merlo, E., Pich, M., Koob, G. F., Yee, F. \& Heilig, M. (1993a). Modulation of anxiety and neuropeptide Y-Y1 receptors by antisense oligonucleotides. Science 259, 528-531.

Wahlestedt, C., Golanov, E., Yamamoto, S., Yee, F., Ericson, H., Yoo, H., Inturrisi, C. E. \& Reis, D. J. (1993b). Antisense oligodeoxynucleotides to NMDA-R1 receptor channel protect cortical neurons from excitotoxicity and reduce focal ischaemic infarctions. Nature 363, 260-263.

Weintraub, H. M. (1990). Antisense RNA and DNA. Scientific American 262, 34-40.

Weiss, B., Zhou, L.-W., Zhang, S.-P. \& Qin, Z.-H. (1993). Antisense oligonucleotide inhibits $\mathrm{D}_{2}$ receptor-mediated behavior and $\mathrm{D}_{2}$ messenger RNA. Neuroscience 55, 607-612.

Whitesell, L., Geselowitz, D., Chavany, C., Fahmy, B., Walbridge, S., Alger, J. R. \& Neckers, L. M. (1993). Stability, clearance, and disposition of intraventricularly administered oligodeoxynucleotides: implications for therapeutic application within the central nervous system. Proceedings of the National Academy of Sciences, USA 90, 4665-4669.

Zhu, N., Liggitt, D. \& Debs, R. (1993). Systemic gene expression after intravenous DNA delivery into adult mice. Science 261, 209-212. 